\title{
Pedalling downhill and freewheeling up; a penguin perspective on foraging
}

\author{
Rory P. Wilson ${ }^{1, *}$, Emily L. C. Shepard ${ }^{1}$, Agustina Gómez Laich ${ }^{2}$, Esteban Frere ${ }^{3}$, \\ Flavio Quintana ${ }^{2,4}$ \\ ${ }^{1}$ Institute of Environmental Sustainability, School of the Society and Environment, Swansea University, Singleton Park, \\ Swansea SA2 8PP, UK \\ ${ }^{2}$ Centro Nacional Patagónico - CONICET, (9120) Puerto Madryn, Chubut, Argentina \\ ${ }^{3}$ Centro de Investigaciones de Puerto Deseado, Universidad Nacional de la Patagonia Austral cc 238, Puerto Deseado, \\ Santa Cruz, Argentina \\ ${ }^{4}$ Wildlife Conservation Society, 2300 Southern Boulevard, New York, New York 10460, USA
}

\begin{abstract}
Depth-dependent buoyancy resulting from the compression of body-associated air is a major force modulating energy expenditure in diving seabirds, yet quantification of its effects in freeliving animals is problematic. Between November 2006 and December 2008, we used multiple channel loggers (daily diaries [DDs]); recording triaxial acceleration, depth and speed, during foraging of 34 Magellanic penguins Spheniscus magellanicus from 3 colonies in Argentina to derive a new proxy for energy expenditure, overall dynamic body acceleration (ODBA). Assuming ODBA to be linearly related to power, energy expenditure was highest during dive descent, nearer the surface and in those dives terminating at greater depths due to steeper descent angles. Swim speed during descent was invariant of maximum dive depth. Calculated energy expenditure during the bottom phase of the dive was invariant of depth, but energy expenditure of birds returning to the surface was lowest at any given depth for birds that had engaged in deeper dives due to the effects of buoyancy. Four birds, equipped with beak angle-measuring sensors as part of the DDs, captured $89 \%$ of their prey (normally pelagic school fish) during fast passive ascents using buoyancy to aid in capture. Details from one of these birds showed that this passive ascent occurred at a mean velocity of $1.94 \mathrm{~m} \mathrm{~s}^{-1}$ for a mean of $2.02 \mathrm{~s}$; ascent angles during such rushes were steeper when the bird was deeper, which was presumed to reflect a response to the diminished buoyant force at greater pressures. Passive ascents during prey capture appear to be an important mechanism for Magellanic penguins to capture fastmoving prey with minimal energy expenditure.
\end{abstract}

KEY WORDS: Magellanic penguin · Spheniscus magellanicus · Buoyancy · Energy expenditure · Prey capture $\cdot$ Speed $\cdot$ Depth $\cdot$ Foraging

Resale or republication not permitted without written consent of the publisher

\section{INTRODUCTION}

Consideration of the best way for animals to acquire food has been the subject of intense debate since the seminal work edited by Krebs \& Davies (1997) formalized the concept of optimal foraging. Since then, the complexities relevant for optimized foraging have made it clear that solutions may change radically according to how well the animals are informed (Dall et al. 2005) of circumstances such as the motility (Ydenberg \& Dill 1986), temporal variation (Newman et al. 1995) or spatial distribution of food (Fauchald \& Tveraa 2006, Stephens et al. 2007).

Air-breathing, diving marine vertebrates are exposed to very particular conditions during foraging. They have to partition their time into periods at the surface when they acquire oxygen but cannot obtain food, and periods underwater when they may search for food during which they use up their limited oxygen reserves. The rate at which the oxygen is used up, and therefore the time that the animals can spend underwater searching for food, depends on metabolic rate, 
and this depends, inter alia, on swim speed (Culik et al. 1994, Schmid et al. 1995) and buoyancy (Lovvorn 1999, Lovvorn et al. 1999, Watanuki et al. 2005). That both swim speed and buoyancy should modulate metabolic rate is a physical certainty (cf. Sato et al. 2002), and this has led to a suite of theoretical studies on how diving animals should best allocate effort and time to maximize foraging success (e.g. Mori 1998, Mori et al. 2002, Halsey et al. 2003, Heath et al. 2007), but quantification of the energetic costs of both is problematic.

Authors such as Ancel et al. (2000) have looked at metabolic rate as a function of swim speed using water flumes; others, such as Culik et al. (1991, 1996), used a still-water swim channel to document how energy expenditure changes with speed in a suite of airbreathing diving animals ranging from penguins to beavers (e.g. Allers \& Culik 1997, Bethge et al. 1997, Borgwardt \& Culik 1999). However, all animals used in such experiments were obliged to swim underwater at shallow depths (around $0.5 \mathrm{~m}$ ) so that buoyancy issues, which change substantially with depth in animals that contain appreciable body volumes of air, particularly birds (Wilson et al. 1992), could not be addressed. Experimental attempts to determine how buoyancy relates to metabolic power in deeper tanks which allow such birds to move freely in 3 dimensions have been fraught by the complexities of how the recorded costs relate to both the mechanical work used for speed and in counteracting buoyancy as well as changes in thermoregulatory costs that vary with plumage thickness which, itself, varies with depth (e.g. Enstipp et al. 2006a). This latter problem is particularly germane in cormorants which have minimal insulation in wettable plumage (Gremillet et al. 2005) and which have been used extensively in work of this type (Schmid et al. 1995, Enstipp et al. 2006a,b, 2007).

The present study used a relatively new measure of the metabolic cost of mechanical power to examine the costs of foraging in free-living penguins. The measure is based on the principle that the extent of muscular contraction involved in body movement produces a corresponding dynamic acceleration of the whole body. Quantification of this overall dynamic body acceleration (ODBA), which can be measured by triaxial accelerometers attached to animals, should thus correlate with metabolic power (Wilson et al. 2006). Indeed, various authors have shown good linear fits between the rate of oxygen consumption and ODBA for 12 very different species (including cormorants, ducks, penguins, rodents, lagomorphs and pinnipeds; Fahlman et al. 2008, Halsey et al. 2008, 2009a,b, Green et al. 2009).

In the present study we used triaxial acceleration data taken from deployments of tags on foraging Magellanic penguins Sphensicus magellanicus. First we derived an estimate for how oxygen consumption relates to ODBA using published data on the rate of oxygen consumption $\left(\mathrm{VO}_{2}\right)$ measurements from swimchannel birds under defined conditions together with our ODBA measurements from free-living penguins exhibiting equivalent behaviours. We then examined how Magellanic penguin dive performance (e.g. rate of change of depth, speed versus metabolic power) affects oxygen consumption. Finally, we used data from beak angle sensors deployed on penguins (Wilson et al. 2002b) as indicators of prey capture to see how birds perform to catch prey and how this relates to oxygen usage, and considered whether the approach managed oxygen reserves judiciously.

\section{MATERIALS AND METHODS}

Fieldwork. Data were collected from 34 Magellanic penguins Spheniscus magellanicus brooding small chicks at 3 colonies (San Lorenzo, $42^{\circ} 04^{\prime} \mathrm{S}, 63^{\circ} 21^{\prime} \mathrm{W}$, $\mathrm{n}=7$ birds; Bahia Bustamante, $45^{\circ} 10^{\prime} \mathrm{S}, 66^{\circ} 30^{\prime} \mathrm{W}, \mathrm{n}=$ 19; San Julian, $49^{\circ} 16^{\prime} \mathrm{S}, 67^{\circ} 42^{\prime} \mathrm{W}, \mathrm{n}=8$ ) in Patagonia, Argentina between November 2006 and December 2008 inclusive. Birds were carefully removed from their nests before being equipped with multichannel archival tags, called daily diaries (DD; Wilson et al. 2008), using overlapping strips of Tesa tape (Wilson et al. 1997). The devices (max. dimensions $70 \times 40 \times$ $10 \mathrm{~mm}$, constituting $3.8 \%$ of the penguin crosssectional area, mass $=68 \mathrm{~g}$, given a streamlined shape) were placed on the lower back, dorsal midline, to minimize drag (Bannasch et al. 1994), and the complete fitting procedure took ca. $4 \mathrm{~min}$.

A subset of these birds $(n=8)$ was additionally fitted with inter-mandibular angle sensors (IMASEN) (Wilson et al. 2002b). These units consist of a Hall sensor $(4 \times 4 \times 2 \mathrm{~mm})$ linked by a cable $(350 \times 3 \mathrm{~mm}$, length $\times$ diameter) to the main body of the DD. The Hall sensor was glued (Poxipol) to the dorsal surface of the upper beak and the cable between the sensor and the main DD body was fixed to the head, neck and upper back of the penguin, at ca. $5 \mathrm{~cm}$ intervals, using small strips of Tesa tape attaching it to 2 or 3 feathers. A small neodinium boron magnet $(5 \times 2 \mathrm{~mm}$, diameter $\times$ width $)$ was glued to the lower beak directly opposite the Hall sensor. After attachment, the Hall sensor, which acts as a transducer for magnetic field strength, was calibrated by using an aluminium rod of variable diameter, graded in $2.5 \mathrm{~mm}$ steps (5 to $25 \mathrm{~mm}$ ), placed between the penguin mandibles. The exact time the beak was open for each diameter was noted, as well as the distance between the calibration rod and the beak articulation, so that beak angle (calculated using simple trigonometry) could be equated with Hall sensor out- 
put (for details see Wilson et al. 2002b). The procedure for fitting penguins with IMASEN-facilitated DDs took ca. 14 min.

After being equipped, birds were replaced on the nest, where they all continued brooding immediately. They were left to undertake a single foraging trip (typically 24 to $36 \mathrm{~h}$ ) before being recaptured and the devices removed.

The DDs recorded data at 6 to $9 \mathrm{~Hz}$ in 13 or 16 channels (for the standard and IMASEN-enabled DDs, respectively) with 22 bit resolution. Recording channels relevant for the present study were triaxial body acceleration (range $=-4$ to $4 \mathrm{~g}$ ) (Gómez Laich et al. 2008, Shepard et al. 2008a), pressure (0.5 to 20 bar), speed (via a flexible silastic paddle, 0 to $6 \mathrm{~m} \mathrm{~s}^{-1}$; Shepard et al. 2008c) and Hall effect (Wilson et al. 2002b). Accuracy on all channels was better than $1 \%$ of fullscale deflection except for depth, where accuracy was better than $0.01 \%$.

Data treatment. Data from the DDs were analyzed using SNOOP software, which displays all recorded channels as a function of time in the form of stacked graphs. This programme allows the user to scroll through the data and isolate and analyse single or multiple dives, exporting the analysed data in standard spreadsheet format. Dives were examined visually to identify those that consisted of smooth descents and ascents, where no prey were captured and where penguin power requirements were likely to be related solely to the process of transit. These were separated from dives where prey were captured, as indicated by the IMASEN or by undulations in the dive profile (Simeone \& Wilson 2003), where the process of prey pursuit was treated specifically. Data examined were depth, rate of change of depth (vertical velocity), dive and return-to-surface angle, swim speed and ODBA. ODBA was calculated by isolating the static component of the total acceleration in each acceleration axis (surge, heave and sway) by smoothing the raw data with a running mean over $2 \mathrm{~s}$ (Shepard et al. 2008b). The dynamic component in each channel was then derived by subtracting the static component from the raw data and this was converted to its absolute value. These absolute values were then summed from all 3 channels to provide the ODBA (for details see Wilson et al. 2006). Data exported from SNOOP were further analysed statistically in Origin Pro 8 (Origin Lab).

We converted ODBA values from Magellanic penguins into power, assuming a linear relationship between ODBA and metabolic power (Wilson et al. 2006, Fahlman et al. 2008, Halsey et al. 2008, Green et al. 2009), and by using data from Luna-Jorquera \& Culik (2000). These latter authors reported the relationship between mass-specific metabolic power and swim speed for congeneric Humboldt penguins Spheniscus humboldti swimming underwater in a still-water swim channel. We isolated 2 points from their polynomial best-fit regression, one corresponding to resting metabolic rate in water with a value of $23.8 \mathrm{~W} \mathrm{bird}^{-1}$ (assuming that Magellanic penguins weigh $4 \mathrm{~kg}$; Williams 1995) and another corresponding to a swim speed of $1.7 \mathrm{~m} \mathrm{~s}^{-1}$ (the mean swimming speed of Magellanic penguins; Wilson et al. 2004), which corresponded to a power of $59.3 \mathrm{~W}$. Given that the penguins used in Luna-Jorquera \& Culik (2000) were obliged to swim at a depth of about $0.5 \mathrm{~m}$ due to the restrictions of the swim channel, and that depth modulates energy expenditure (Lovvorn 1999), we then searched for periods in our data when free-living Magellanic penguins were swimming horizontally at $1.7 \mathrm{~m} \mathrm{~s}^{-1}$ and $0.5 \mathrm{~m}$ depth and calculated the relevant ODBA values. ODBA values for resting Magellanic penguins were taken during resting periods of the birds on land since the wave action on birds at sea introduces a dynamic acceleration component that is independent of muscular activity. The values for resting Magellanic penguin ODBA and those for swimming underwater under the defined conditions were then used in a simple regression of ODBA versus metabolic power.

The IMASEN-derived data showed clearly when birds had ingested prey rather than simply snapped at it because successful capture resulted in undulations in the graph of beak angle over time over the latter part of the ingestion event. Work with penguins in captivity has shown that these undulations are due to the birds moving the fish down the throat past the rictus in a series of gulps where the beak is momentarily opened (Wilson et al. 2002b, R. P. Wilson et al. unpubl. data). In fact, free-living Magellanic penguins snap at and miss prey less than $1 \%$ of the time.

Means are presented \pm SD unless otherwise specified.

\section{RESULTS}

\section{Relationship between ODBA and metabolic power}

Inspection of all data from all birds showed that there were few occasions when Magellanic penguins actually swam at $0.5 \mathrm{~m}$ depth (using limits between 0.4 and $0.6 \mathrm{~m}$ ) horizontally. Indeed, most dives, even those that were considered shallow, exceeded $1 \mathrm{~m}$. However, a total of 12 birds performed at least one dive that met the requirements for calculating OBDA, i.e. swimming horizontally at $1.7 \mathrm{~m} \mathrm{~s}^{-1}$ and $0.5 \mathrm{~m}$ depth. Regressing their ODBA values (one per bird) against the power values $(P, \mathrm{~W})$ cited for those conditions $\left(\mathrm{r}^{2}=0.98, \mathrm{p}<\right.$ $0.001 ; F=1302, \mathrm{p}<0.001)$ gave a relationship of:

$$
P=117.7 \mathrm{ODBA}+22.0
$$




\section{Description of dive parameters}

Descent phase

During the descent phase of the dive, birds showed systematic changes in most measured parameters as a function of both maximum depth reached and depth at any one time during the descent. For instance, birds terminating their dives at deeper depths descended the water column faster ( $F=16341, \mathrm{p}<0.001)$ (Fig. 1a). This was modulated primarily by descent angle, which was steeper in birds terminating dives at deeper depths $(F=859$, p < 0.001) (Fig. 1b), while actual swim
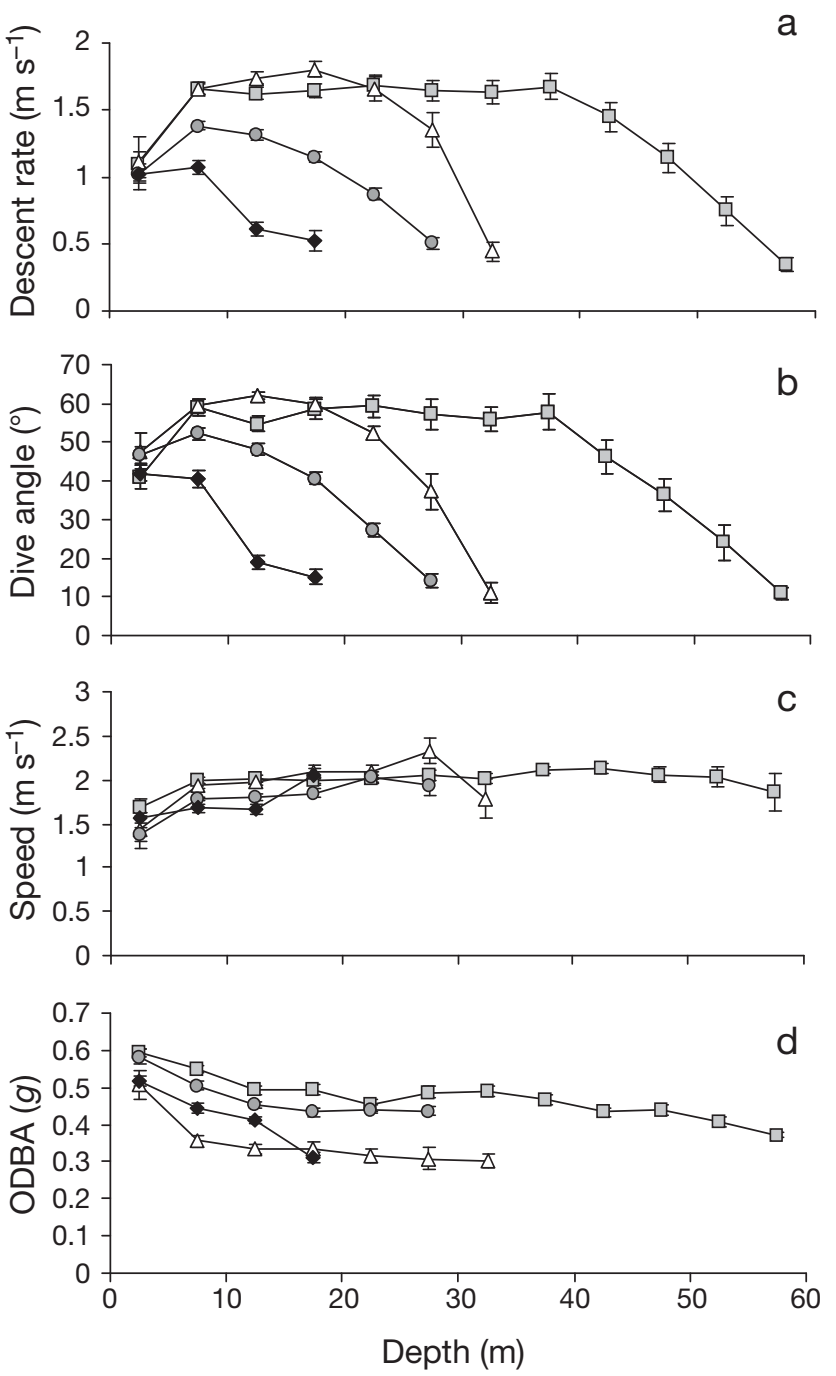

Fig. 1. Spheniscus magellanicus. (a) Rate of descent (b) dive angle (c) swim speed and (d) overall dynamic body acceleration (ODBA) as a function of depth for the descent phase of Magellanic penguins for dives terminating at different depths (the deepest point in any of the relationships shows the maximum depth range). Different symbols show means derived from a number of penguins all terminating dives within $5 \mathrm{~m}$ of the maximum indicated. Error bars are $\pm \mathrm{SE}$ speed was essentially invariant of the maximum depth reached during the dive and varied little over the course of the descent ( $p>0.1$ ) (Fig. 1c). In tandem with the maximum depth-linked variable descent rates, ODBA also varied systematically with both maximum depth reached during the dive $(F=1271, \mathrm{p}<0.001)$ and depth at any time during the descent, with values being higher for deeper dives ( $F=464, \mathrm{p}<0.001)$ (Fig. 1d).

\section{Bottom phase}

During the bottom phase of the dive there was no relationship between rate of change of depth, swim angle, swim speed and ODBA and maximum depth $(\mathrm{p}>0.1)$. The mean ODBA value was $0.196 \pm 0.077 \mathrm{~g}$ (Fig. 2).

\section{Ascent phase}

Vertical velocity. Rates of ascent (rates of change of depth) varied according to the maximum depth reached during the dive and the instantaneous depth at any one time during the ascent (Fig. 3a). Typically, birds started the ascent slowly, at speeds of ca. $0.5 \mathrm{~m}$ $\mathrm{s}^{-1}$, but then systematically speeded up for the rest of the ascent except for the last $5 \mathrm{~m}$, just below the surface, where rates of change of depth dropped again (Fig. 3a). These lower values at the onset and end of the ascent were not due to running mean problems, as was made clear by the high sampling rate (minimum of $6 \mathrm{~Hz}$ ). Second-order polynomial fits of the vertical velocity $\left(v_{\text {vert }}, \mathrm{m} \mathrm{s}^{-1}\right)$ versus instantaneous depth $\left(z_{\text {inst }}\right.$, $\mathrm{m})$ data followed:

$$
V_{\text {vert }}=k_{1}\left(Z_{\text {inst }}\right)^{2}+k_{2}\left(Z_{\text {inst }}\right)+k_{3}
$$

which gave $\mathrm{r}^{2}$-values always in excess of 0.76 for dives grouped into $10 \mathrm{~m}$ maximum depth bins ( $\mathrm{p}<0.01$ ). Beyond this, the constants $\left(k_{1}, k_{2}\right.$ and $\left.k_{3}\right)$ from these

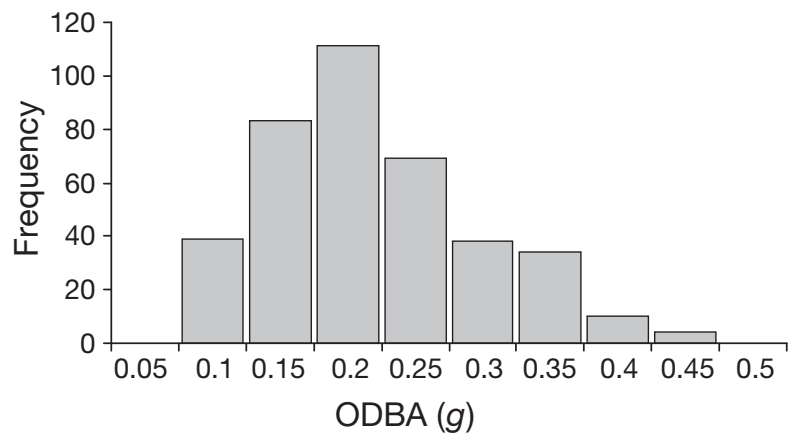

Fig. 2. Spheniscus magellanicus. Frequency distribution of overall dynamic body acceleration (ODBA) values of Magellanic penguins during the bottom phase of 387 dives during which no prey were considered pursued 

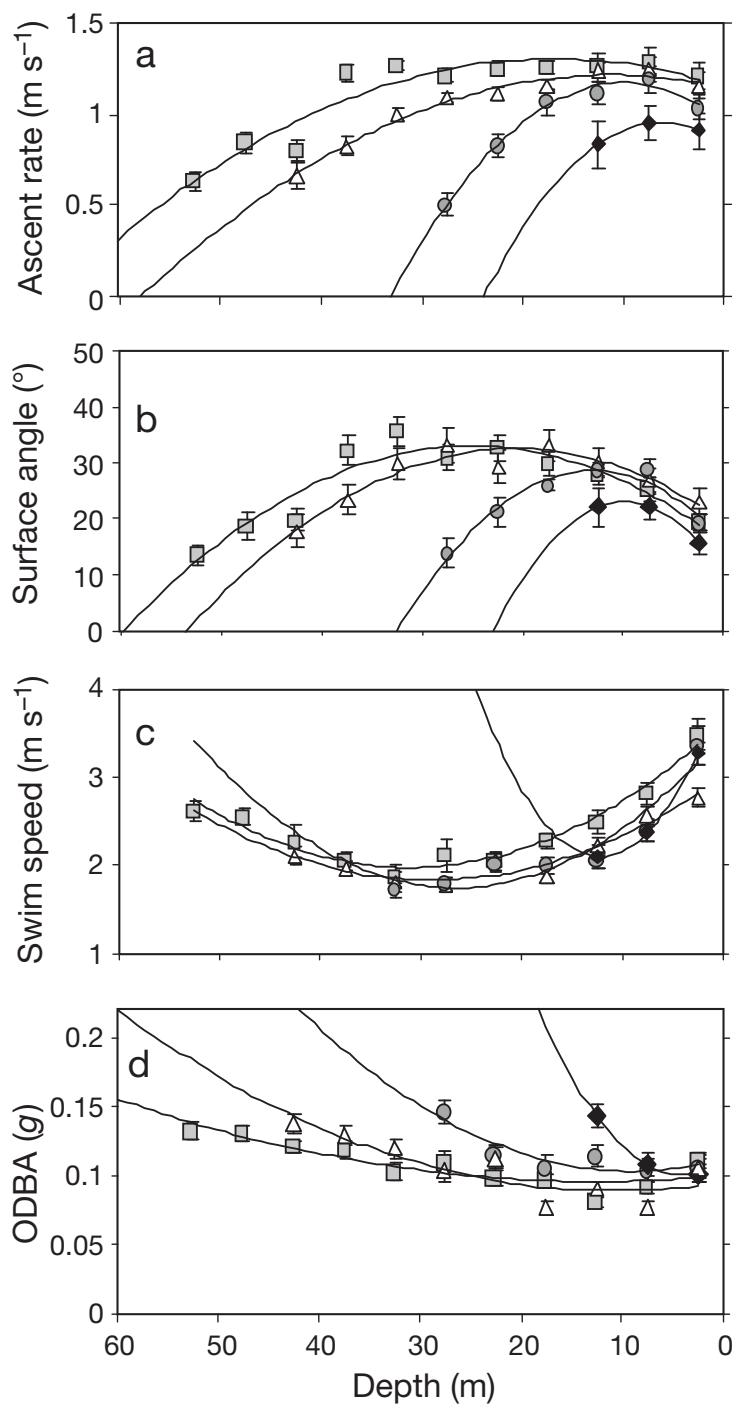

Fig. 3. Spheniscus magellanicus. (a) Rate of ascent, (b) returnto-surface surface angle, (c) swim speed and (d) overall dynamic body acceleration (ODBA) as a function of depth for Magellanic penguins ascending to the surface after executing dives to different depths. Different symbols show means derived from a number of penguins all terminating dives within $5 \mathrm{~m}$ of the maximum indicated. Data are means $\pm \mathrm{SE}$ per depth class. Associated curves are best-fit second-order polynomials whose regression parameters are detailed in Table 1

polynomial fits varied systematically with maximum depth groupings (Table 1) so that the vertical velocity of surfacing Magellanic penguins could be described in terms of the maximum depth reached $\left(z_{\max }, \mathrm{m}\right)$ by:

$$
\begin{aligned}
V_{\text {vert }} & =\left\{-\left[-0.0019 \ln \left(z_{\text {max }}\right)+0.0079\right]\right\} z_{\text {inst }}^{2} \\
& +\left(-0.0007 z_{\max }+0.0513\right) z_{\text {inst }}+0.0087 z_{\max }+0.69
\end{aligned}
$$

Ascent angle. Rates of ascent were modulated primarily by ascent angle, which also varied according to the maximum depth reached during the dive $(F=542$,
Table 1. Constants of second-order polynomial fits (following $y=k_{1} z_{\text {inst }}{ }^{2}+k_{2} z_{\text {inst }}+k_{3}$, where $z_{\text {inst }}$ is the instantaneous depth) to describe how the $y$-parameters (vertical velocity, ascent angle, swim speed and overall dynamic body acceleration [ODBA]) change with instantaneous depth and maximum depth $\left(z_{\max }, \mathrm{m}\right)$ reached during a dive

\begin{tabular}{|llc|}
\hline$y$-parameter & \multicolumn{1}{c|}{ Value of constant } & $\mathrm{r}^{2}$ \\
\hline Vertical velocity & $k_{1}=-\left[-0.0019 \ln \left(z_{\max }\right)+0.0079\right]$ & 0.88 \\
$\left(\mathrm{~m} \mathrm{~s}^{-1}\right)$ & $k_{2}=-0.0007 z_{\max }+0.0513$ & 0.63 \\
& $k_{3}=0.0087 z_{\max }+0.6969$ & 0.75 \\
Ascent angle $\left(^{\circ}\right)$ & $k_{1}=-\left[-0.0791 \ln \left(z_{\max }\right)+0.3296\right]$ & 0.93 \\
& $k_{2}=9.8258 z_{\max }{ }^{-0.5163}$ & 0.91 \\
& $k_{3}=0.1697 z_{\max }+9.2648$ & 0.51 \\
Swim speed & $k_{1}=0.4712 z_{\max }-1.5007$ & 0.92 \\
$\left(\mathrm{~m} \mathrm{~s}^{-1}\right)$ & $k_{2}=-2.1303 z_{\max }-0.8238$ & 0.81 \\
& $k_{3}=-0.0102 z_{\max }+3.7774$ & 0.17 \\
ODBA $(g)$ & $k_{1}=-0.1037 z_{\max }-2.058$ & 0.99 \\
& $k_{2}=0.0028 \ln \left(z_{\max }\right)-0.0116$ & 0.97 \\
& $k_{3}=-0.0004 z_{\max }+0.121$ & 0.22 \\
\hline
\end{tabular}

$\mathrm{p}<0.001$ ), and the instantaneous depth at any time during the ascent $(F=129, \mathrm{p}<0.001)$ (Fig. 3b). Typically, birds started the ascent at angles of ca. $15^{\circ}$, increasing angles to about $35^{\circ}$, though this value was higher for deeper dives (Fig. 3b), at approximately the mid-point of the return to the surface trajectory, before the angle decreased again to around $20^{\circ}$ just before the birds surfaced (Fig. 3b). Second-order polynomial equations (see Eq. 2) described the changing angles over depth well (with $\mathrm{r}^{2}$-values always in excess of 0.88 ) and the 3 constants varied systematically with maximum depth groupings in a similar manner to vertical velocity (Table 1$)$. Thus, ascent angle $\left(A_{\mathrm{asc} \text { I- }^{\circ}}{ }^{\circ}\right)$ could be described by:

$$
\begin{aligned}
A_{\mathrm{asc}} & =\left\{-\left[-0.0791 \ln \left(z_{\max }\right)+0.3296\right]\right\} z_{\text {inst }}^{2} \\
& +\left(9.8258 z_{\max }{ }^{-0.5163}\right) z_{\text {inst }}+0.1697 z_{\max }+9.26
\end{aligned}
$$

\section{Swim speed}

Swim speed varied little between dives to different depths ( $p>0.05)$, but showed systematic changes with depth during the trajectory from the deepest part of the dive to the surface, starting at values between 2 and $2.5 \mathrm{~m} \mathrm{~s}^{-1}$ and tending to increase with decreasing depth (up to values of almost $3.5 \mathrm{~m} \mathrm{~s}^{-1}$ just before reaching the surface) ( $F=1848, \mathrm{p}<0.001)$ (Fig. 3c). Second-order polynomial equations described the changing speeds over depth well (with $\mathrm{r}^{2}$-values always in excess of 0.77 ) and the 3 constants varying systematically with maximum depth groupings (Table 1). Thus swim speed $\left(S, \mathrm{~m} \mathrm{~s}^{-1}\right)$ could be described by:

$$
\begin{aligned}
S & =\left(0.4712 z_{\max }{ }^{-1.501}\right) Z_{\text {inst }}{ }^{2}-\left(2.1303 z_{\max }{ }^{-0.8238}\right) Z_{\text {inst }} \\
& -0.0102 z_{\max }+3.78
\end{aligned}
$$




\section{ODBA}

ODBA varied with maximum dive depth $(F=2457$, $\mathrm{p}<0.001)$ and instantaneous depth $(F=3169, \mathrm{p}<$ 0.001) (Fig. 3d) in a manner similar to the other parameters examined (Table 1) so that ODBA could be described by:

$$
\begin{aligned}
\text { ODBA } & =\left(-0.1037 z_{\text {max }}{ }^{-2.058}\right) z_{\text {inst }}{ }^{2}+\left[0.0028 \ln \left(z_{\text {max }}\right)\right. \\
& -0.012] z_{\text {inst }}-0.0004 z_{\max }+0.12
\end{aligned}
$$

\section{Prey capture}

All penguins equipped with DDs showed undulations in the depth profile (Fig. 4). Only 4 of those equipped with IMASEN maintained the beak angle sensors in place long enough to record prey capture, 3 of which did not stay in place for the full duration of the foraging trip; but all showed that the undulations were associated with prey capture (Fig. 4), as has been already reported for this species by Simeone \& Wilson (2003). Consideration of 192 random prey capture events by the single bird for which the complete foraging trip was recorded (which constitutes half of all its prey captures) showed that on 171 occasions ( $89 \%$ ) the prey were taken on the upsurge, on 17 occasions $(9 \%)$ during straight pursuit and on 4 occasions $(2 \%)$ on the downsurge $\left(\chi^{2}=121.6, p<0.001\right)$. Detailed assessment of 70 prey items taken by this bird (the cases where a clear point of inflection indicated where the bird began to react to the prey) showed that the upsurge preced-

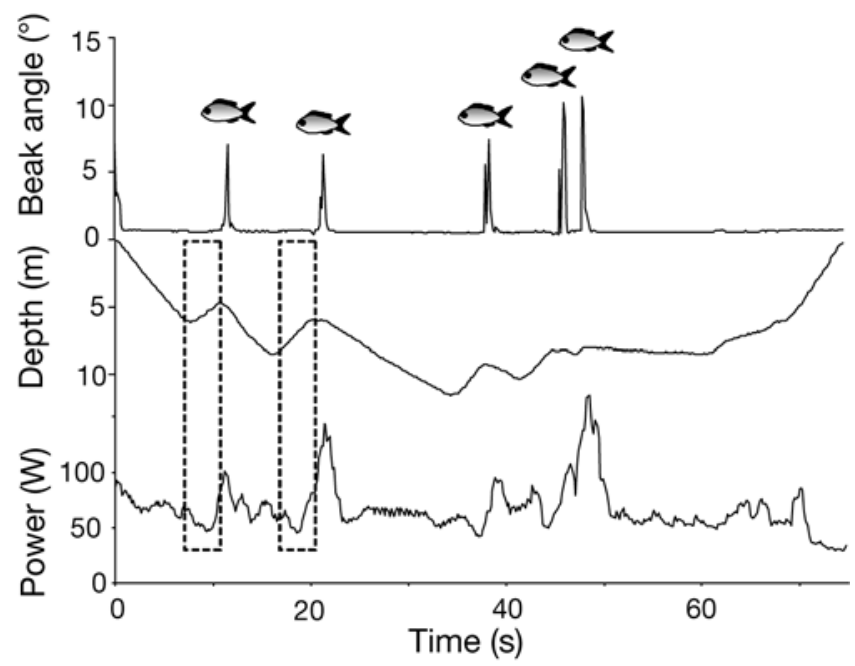

Fig. 4. Spheniscus magellanicus. Prey captures by a Magellanic penguin, as indicated by increases in intermandibular beak angle (upper) as a function of time into a dive (indicated by depth; middle) and instantaneous power (lower) derived from overall dynamic body acceleration (ODBA) (Eq. 1). Note the decrease in depth and low power values immediately preceding the ingestion events ( 2 examples are delineated by the dashed boxes) ing prey capture took a mean of $2.02 \pm 0.62 \mathrm{~s}$ at a mean swim speed of $1.94 \pm 0.51 \mathrm{~m} \mathrm{~s}^{-1}$. Swim speed during these manoeuvres was not related to depth at which this occurred (depth taken to be the mid-point of the upsurge; $F=0.23, \mathrm{p}>0.05$ ), but rate of change of depth (or $\left.V_{\text {vert }}\right)$ was significantly related to this depth $\left(\mathrm{r}^{2}=\right.$ $0.22, F=21.63, \mathrm{p}<0.001$ ) (Fig. 5a) according to:

$$
V_{\text {vert }}=0.014 z+0.7
$$

This was primarily modulated by swim angle $\left(A_{\text {swim }}{ }^{\circ}\right)$, which was positively related to depth $(z)$ during the upsurge $\left(\mathrm{r}^{2}=0.38, F=40.13, \mathrm{p}<0.001\right)$ (Fig. 5b) according to:
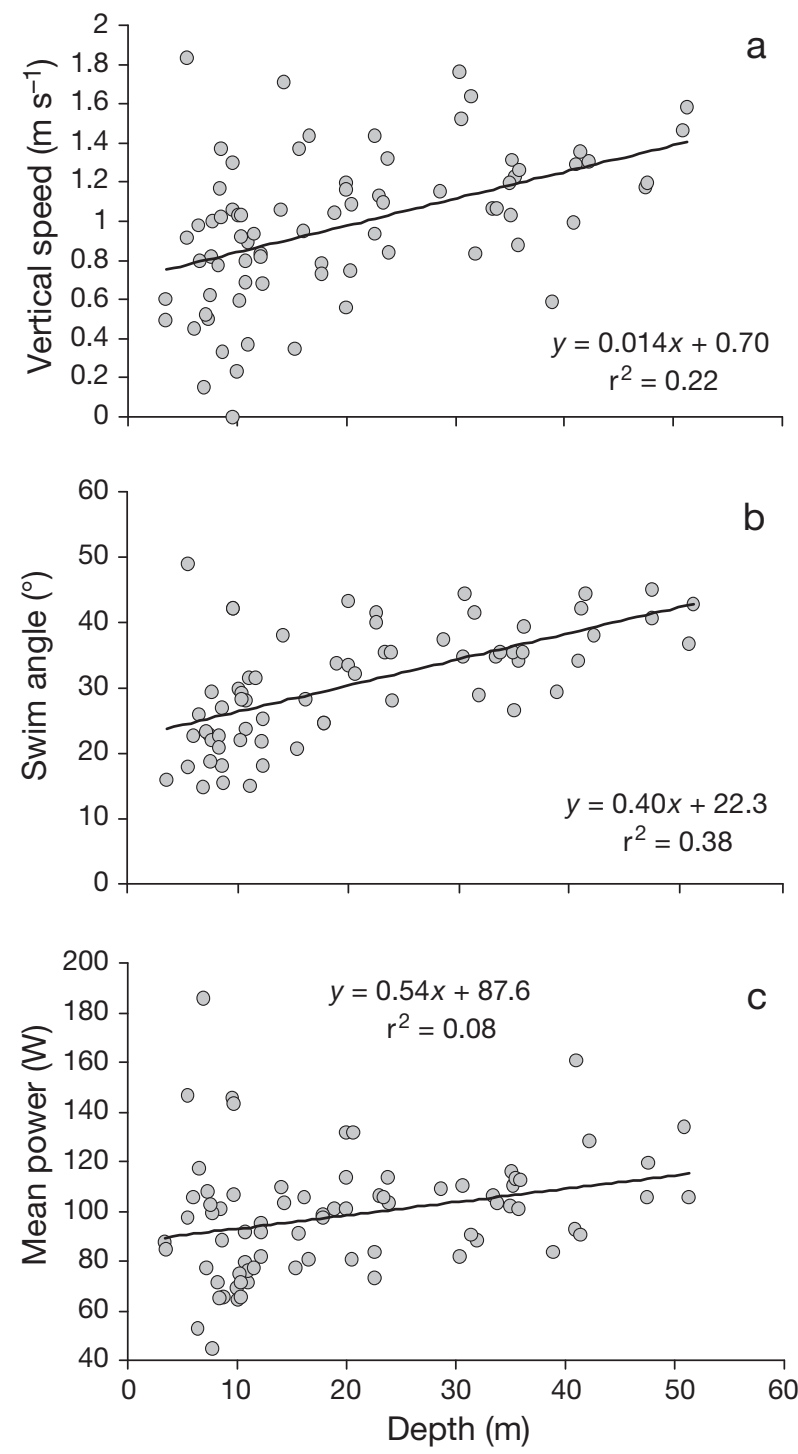

Fig. 5. Spheniscus magellanicus. Relationship between (a) vertical speed, (b) swim angle and (c) calculated metabolic power (see Eq. 1) and depth for upwardly directed rushes (upsurges) terminating in prey capture in a Magellanic penguin foraging on pelagic prey 


$$
A_{\text {swim }}=0.4 z+22.3
$$

although the ODBA during the upsurge also increased significantly, though marginally, with increasing depth $(F=6.72, \mathrm{p}<0.05)$. If ODBA is converted to power using Eq. (1), mean power use $\left(P_{\text {mean }}, \mathrm{W}\right)$ during the upsurge is calculated to be related to depth (Fig. 5c) according to:

$$
P_{\text {mean }}=0.54 z+87.6
$$

\section{DISCUSSION}

The treatise attempted here is based on the assumption that ODBA relates linearly to metabolic rate, as has been shown for 10 terrestrial animals (e.g. Halsey et al. 2008, Green et al. 2009) and 1 swimming animal (Fahlman et al. 2008).

Our work shows how energy expenditure during the descent phase of the dive might be related to buoyancy (via depth-linked changes in pressure affecting air spaces) and performance expressed as rate of change of depth (Fig. 1a), which is primarily modulated by descent angle (Fig. 1b) as speed is virtually constant (Fig. 1c). The descent rates that we recorded for Magellanic penguins during the present study concur with those reported for this species by other authors (Peters et al. 1998, Radl \& Culik 1999, Walker \& Boersma 2003), i.e. higher descent and ascent rates with increasing maximum depth reached. Work on other penguin species, where either measured speed allows access to descent and/or ascent angles or where the body angle can be measured directly via static acceleration, indicates that rates of descent and ascent are indeed modulated primarily by angle rather than speed (Ropert-Coudert et al. 2001b, Sato et al. 2004). In accordance with this, ODBA, and therefore metabolic power, was higher in birds diving deeper in all phases of the descent (Fig. 6). However, this is unlikely to be just a function of the descent rate. Wilson \& Zimmer (2004) report that Magellanic penguins inhale more respiratory air for deeper dives (cf. Sato et al. 2002) and our birds showed no change in ODBA during the bottom phase as a function of depth (cf. Fig. 2), which suggests they followed this pattern. Thus it would appear that the higher metabolic power in deeper-diving penguins (Fig. 6) is also the result of them taking a higher volume of inspired air faster down the water column.

The situation was more complex during ascent, although, again, swim speed at any depth varied little between dives stemming from different maximum depths (Fig. 3b). We note that ascent speeds were markedly higher than descent speeds, particularly near the surface (cf. Figs. 1c \& 3c). During the ascent, rates of change of depth were higher at any given

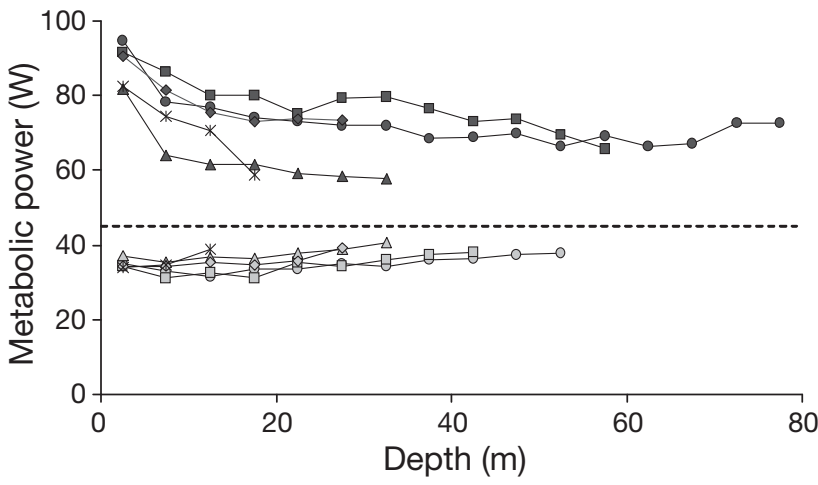

Fig. 6. Spheniscus magellanicus. Estimated metabolic power used by Magellanic penguins during descent and ascent in dives reaching different maximum depths (indicated by the point at which the lines terminate). Values are calculated using the overall dynamic body acceleration (ODBA) values taken from the study birds shown in Figs. $1 d$ \& $3 d$ for descent (black symbols) and ascent (grey symbols), respectively, and transformed by $P=117.7$ ODBA +22.0 (Eq. 1). The horizontal dashed line shows the estimated metabolic power for birds swimming horizontally at any depth and was estimated by transforming the mean ODBA for horizontal swimming of $0.196 \mathrm{~g}$ using Eq. (1)

depth in deeper-diving birds, this being primarily modulated by the return-to-surface angle. Sato et al. (2002) and Wilson \& Zimmer (2004) (cf. Watanuki et al. 2006) report cessation of flipper beating during the ascent phase of dives at a specific point where the buoyancy of the expanding air associated with the body is enough to propel the bird to the surface passively. The ODBA converted to metabolic power values from the present study (using Eq. 1) illustrated this process (Fig. 6), where the rate of energy expenditure was markedly less than at any time during the descent. Again, it is notable that the metabolic power for the ascent at any given depth was less for deeper-diving individuals, presumably because they were being propelled with more force by the larger amounts of inhaled air acting on a body being directed up at a steeper angle (Fig. 3b).

\section{Overall costs of dives to different depths}

The data accumulated on how dive parameters vary with different maximum depths (Figs. 1 \& 3) allowed us to model cumulative energetic costs for the various phases of dives to different depths. This approach shows that the during any single V-shaped dive (with no bottom phase), the cumulative energy costs initially increase rapidly as the bird descends but, after the penguin has reached the point of maximum depth, the rate of increase of energy expended decreases as the bird returns to the surface (Fig. 7a). The total energy expended for such dives shows a roughly log curve 

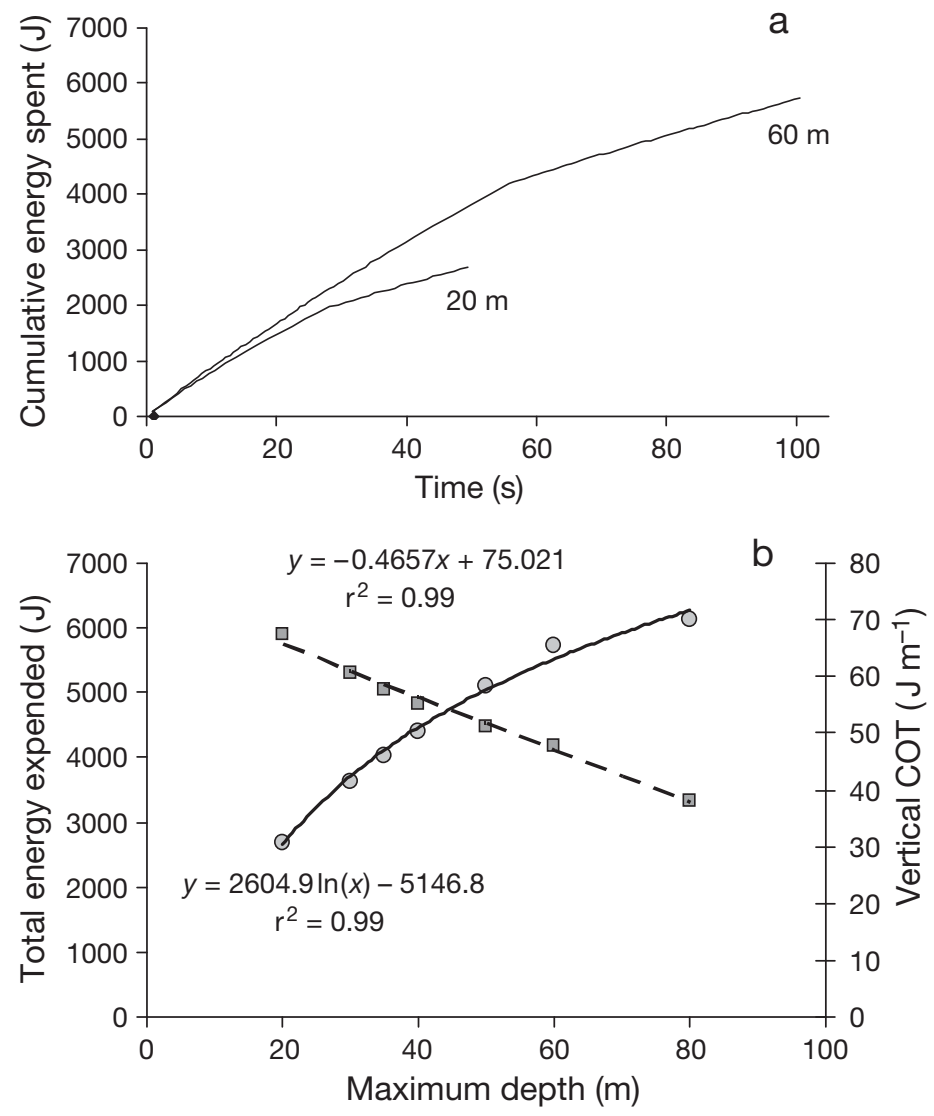

Fig. 7. Spheniscus magellanicus. (a) Cumulative energy expended as a function of time into the dive by a Magellanic penguin executing 2 bounce dives (with no bottom phase) to 2 different maximum depths ( 20 and $60 \mathrm{~m}$, shown by the points of inflection) to highlight how power use varies according to maximum depth of dive; deeper-diving birds use proportionately more power (note the steeper gradient in the $60 \mathrm{~m}$ dive). The data to construct these 2 dives were taken from results obtained in the present study, assuming a linear relationship between overall dynamic body acceleration (ODBA) and metabolic power (Eq. 1). (b) Total energy expended (continuous line, log-type curve) and vertical cost of transport (COT; dashed line, linear fit) as a function of maximum dive depth for Magellanic penguins executing bounce dives

relationship with maximum depth reached, so that the cost of transport in the vertical dimension decreases with increasing maximum depth (Fig. 7b). Thus, per vertical metre travelled, deep dives are more energyefficient for Magellanic penguins than shallow dives. This stems, in part, from more time spent at greater depths where the power required to counteract upthrust is minimized. The greater apparent efficiency of deeper dives does not, however, necessarily mean that Magellanic penguins should favour deeper dives, even if prey were equally distributed down the water column, since transit between the water surface and the foraging depth are not directly profitable. The profitability of different depths is further complicated by the precise prey capture techniques adopted by
Magellanic penguins, which appear to use upthrust, which varies with depth, to minimize energy expenditure during pursuit.

\section{Prey capture}

Penguins of the genus Spheniscus feed on pelagic school fish such as anchovy Engraulis spp., and sardine Sardinops spp. in shoals (Williams 1995 and references therein), and have been reported to catch prey either by herding them or by simply chasing them down (Wilson et al. 1987 and references therein). Assuming the simple pursuit scenario to be generally true, Wilson et al. (2002a) modelled the consequences of power use in rushes and found high metabolic costs because of the way that drag increases as an accelerating function of the speed. Unfortunately, the Wilson et al. (2002a) scenario did not take into account the complicating and profound effects of upthrust; Simeone \& Wilson (2003) reported from studies using IMASEN technology, that $86 \%$ of prey caught by Magellanic penguins were preceded by rushes toward the surface similar to those reported in the present study. This also accords with results published by Wilson \& Duffy (1986) who, after examining bite marks on prey, reported that congeneric African penguins Spheniscus demersus feeding on cape anchovies Engraulis capensis always bit them from the underneath. In fact, capture of prey during surface-directed rushes may be a general feature of penguin foraging ecology because other authors have reported undulations in the depth profile to be indicative of prey capture in emperor Aptenodytes forsteri (Rodary et al. 2000), Humboldt (Luna-Jorquera \& Culik 1999), rockhopper Eudyptes chroscome (Tremblay \& Cherel 2000) and Adélie penguins Pygosccelis adeliae (Ropert-Coudert et al. 2001).

Although Ropert-Coudert et al. (2006) report that little penguins Eudyptula minor head predominantly downward during periods assumed to constitute prey pursuit, possibly to use the seabed to assist them to trap prey, this behaviour seems exceptional among penguins. For example, Bost et al. (2007) noted that king Aptenodytes patagonicus and Adélie penguins catch prey during the ascent phases of undulations and Ropert-Coudert et al. (2001a) report that the general tendency of Adélie penguins to take prey from below can be explained by the birds benefiting from the backlighting of the water surface, against which the prey are presumed to be silhouetted. This seems reason enough to take prey from underneath. However, the present study also showed that by angling their body appropriately toward the surface, Magellanic penguins can use upthrust to drive them toward their prey at speeds appropriate for their capture. This pro- 
cess is most effective near the surface where upthrust is greatest and the rush trajectory of a bird at, say, $10 \mathrm{~m}$, is about $4 \mathrm{~m}$ long at an angle of around $25^{\circ}$. Birds would appear to compensate for the decreased upthrust with increasing depth by increasing their angle of attack (at $50 \mathrm{~m}$, the ascent angle is predicted to be ca. $42^{\circ}$ ), although they also invest more energy in the rush (Fig. 5c). Thus prey caught during upsurges may be caught with the least energy, and therefore oxygen, near the surface. The very few cases where prey are pursued in a downrush will, however, be correspondingly energetically more onerous near the surface. More IMASEN data will allow us to assess whether the incidence of prey pursuit is higher in downrushes with increasing depth. Otherwise, proper calculations on the energetic advantages of using buoyancy to pursue prey should take into account the multiple prey captures of penguins during single dives (Magellanic penguins may take up to 13 prey items in a single dive, Wilson 2003), where the energy gained by rising passively to the surface has to be integrated with the energy used to re-descend to a suitable depth to undertake the manoeuvre again (cf. Fig. 4). Critically though, penguins should be able to modulate the rate of descent so that the vertical cost of transport is minimized to produce an optimum solution, although, given that these birds feed on pelagic fish in schools (Williams 1995), this might depend on the strategy of the prey. Complicated herding and cooperative manoeuvres have been described for Spheniscus penguins feeding on fish (see Wilson et al. 1987), and description of the interaction between birds and prey, particularly now that we might be able to quantify both energetics more closely with ODBA and movement using dead-reckoning (Wilson et al. 2008), promises to be an exciting avenue for future research.

Acknowledgements. This study was made possible by the Rolex Awards for Enterprise and a grant (ECO407-08) by the National Geographic Society.

\section{LITERATURE CITED}

Allers D, Culik BM (1997) Energy requirements of beavers (Castor canadensis) swimming underwater. Physiol Zool 70:456-463

> Ancel A, Starke LN, Ponganis PJ, Van Dam R, Kooyman GL (2000) Energetics of surface swimming in Brandt's cormorants (Phalacrocorax penicillatus Brandt). J Exp Biol 203:3727-3731

Bannasch R, Wilson RP, Culik B (1994) Hydrodynamic aspects of design and attachment of a back-mounted device in penguins. J Exp Biol 194:83-96

Bethge P, Nicol S, Culik BM, Wilson RP (1997) Diving behaviour and energetics in breeding little penguins (Eudyptula minor). J Zool 242:483-502

Borgwardt N, Culik BM (1999) Asian small-clawed otters
(Amblonyx cinerea): resting and swimming metabolic rates. J Comp Physiol B 169:100-106

Bost CA, Handrich Y, Butler PJ, Fahlman A, Halsey LG, Woakes AJ, Ropert-Coudert Y (2007) Changes in dive profiles as an indicator of feeding success in king and Adélie penguins. Deep-Sea Res II 54:248-255

Culik BM, Wilson RP, Dannfeld R, Adelung D, Spairani HJ, Coria NRC (1991) Pygoscelid penguins in a swim canal. Polar Biol 11:277-282

Culik BM, Wilson RP, Bannasch R (1994) Underwater swimming at low energetic cost by pygoscelid penguins. J Exp Biol 197:65-78

Culik BM, Putz K, Wilson RP, Allers D, Lage J, Bost CA, LeMaho Y (1996) Diving energetics in king penguins (Aptenodytes patagonicus). J Exp Biol 199:973-983

Dall SRX, Giraldeau LA, Olsson O, McNamara JM, Stephens DW (2005) Information and its use by animals in evolutionary ecology. Trends Ecol Evol 20:187-193

Enstipp MR, Gremillet D, Jones DR (2006a) The effects of depth, temperature and food ingestion on the foraging energetics of a diving endotherm, the double-crested cormorant (Phalacrocorax auritus). J Exp Biol 209:845-859

Enstipp MR, Gremillet D, Lorentsen SH, Jones DR (2006b) Diving energetics and foraging behavior in cormorants and shags. J Ornithol 147:63-64

Enstipp MR, Jones DR, Lorentsen SH, Gremillet D (2007) Energetic costs of diving and prey-capture capabilities in cormorants and shags (Phalacrocoracidae) underline their unique adaptation to the aquatic environment. J Ornithol 148(Suppl):593-600

Fahlman A, Wilson R, Svard C, Rosen DAS, Trites AW (2008) Activity and diving metabolism correlate in Steller sea lion Eumetopias jubatus. Aquat Biol 2:75-84

Fauchald P, Tveraa T (2006) Hierarchical patch dynamics and animal movement pattern. Oecologia 149:383-395

> Gómez Laich A, Wilson RP, Quintana F, Shepard ELC (2008) Identification of imperial cormorant Phalacrocorax atriceps behaviour using accelerometers. Endang Species Res 10:29-37

Green JA, Halsey LG, Wilson RP, Frappell PB (2009) Estimating energy expenditure of animals using the accelerometry technique: activity, inactivity and comparison with the heart-rate technique. J Exp Biol 212:471-482

Gremillet D, Chauvin C, Wilson RP, Le Maho Y, Wanless S (2005) Unusual feather structure allows partial plumage wettability in diving great cormorants Phalacrocorax carbo. J Avian Biol 36:57-63

> Halsey L, Woakes A, Butler P (2003) Testing optimal foraging models for air-breathing divers. Anim Behav 65: 641-653

> Halsey LG, Shepard ELC, Hulston CJ, Venables MC, White CR, Jeukendrup AE, Wilson RP (2008) Acceleration versus heart rate for estimating energy expenditure and speed during locomotion in animals: tests with an easy model species, Homo sapiens. Zoology 111:231-241

- Halsey LG, Green JA, Wilson RP, Frappell PB (2009a) Accelerometry to estimate energy expenditure during activity: best practice with data loggers. Physiol Biochem Zool 82: 396-404

Halsey LG, Shepard ELC, Quintana F, Laich AG, Green JA, Wilson RP (2009b) The relationship between oxygen consumption and body acceleration in a range of species. Comp Biochem Physiol A 152:197-202

> Heath JP, Gilchrist HG, Ydenberg RC (2007) Can dive cycle models predict patterns of foraging behaviour? Diving by common eiders in an Arctic polynya. Anim Behav 73: $877-884$ 
Krebs JR, Davies NB (1997) Behavioural ecology: an evolutionary approach. Blackwell Science, Oxford

Lovvorn JR (1999) Effects of dive depth, buoyancy, and propulsive mode on the inertial work of swimming in birds. Am Zool 39:14

Lovvorn JR, Croll DA, Liggins GA (1999) Mechanical versus physiological determinants of swimming speeds in diving Brunnich's guillemots. J Exp Biol 202:1741-1752

Luna-Jorquera G, Culik BM (1999) Diving behaviour of Humboldt penguins Spheniscus humboldti in northern Chile. Mar Ornithol 27:67-76

Luna-Jorquera G, Culik BM (2000) Metabolic rates of swimming Humboldt penguins. Mar Ecol Prog Ser 203:301-309

> Mori Y (1998) Optimal choice of foraging depth in divers. J Zool 245:279-283

> Mori Y, Takahashi A, Mehlum F, Watanuki Y (2002) An application of optimal diving models to diving behaviour of Brunnich's guillemots. Anim Behav 64:739-745

> Newman JA, Parsons AJ, Thornley JHM, Penning PD, Krebs JR (1995) Optimal diet selection by a generalist grazing herbivore. Funct Ecol 9:255-268

Peters G, Wilson RP, Scolaro JA, Laurenti S, Upton J, Galleli H (1998) The diving behavior of Magellanic penguins at Punta Norte, Península Valdés, Argentina. Colon Waterbirds 21:1-10

Radl A, Culik BM (1999) Foraging behaviour and reproductive success in Magellanic penguins (Spheniscus magellanicus): a comparative study of two colonies in southern Chile. Mar Biol 133:381-393

Rodary D, Bonneau W, Le Maho Y, Bost CA (2000) Benthic diving in male emperor penguins Aptenodytes forsteri foraging in winter. Mar Ecol Prog Ser 207:171-181

Ropert-Coudert Y, Kato A, Baudat J, Bost CA, Le Maho Y, Naito Y (2001a) Feeding strategies of free-ranging Adélie penguins Pygoscelis adeliae analysed by multiple data recording. Polar Biol 24:460-466

Ropert-Coudert Y, Kato A, Baudat J, Bost CA, Le Maho Y, Naito Y (2001b) Time/depth usage of Adélie penguins: an approach based on dive angles. Polar Biol 24:467-470

Ropert-Coudert Y, Kato A, Wilson RP, Cannell B (2006) Foraging strategies and prey encounter rates of free-ranging little penguins. Mar Biol 149:139-148

Sato K, Naito Y, Kato A, Niizuma Y and others (2002) Buoyancy and maximal diving depth in penguins: Do they control inhaling air volume? J Exp Biol 205:1189-1197

Sato K, Charrassin JB, Bost CA, Naito Y (2004) Why do macaroni penguins choose shallow body angles that result in longer descent and ascent durations? J Exp Biol 207: 4057-4065

Schmid D, Gremillet DJH, Culik BM (1995) Energetics of underwater swimming in the great cormorant (Phalacrocorax-carbo-sinensis). Mar Biol 123:875-881

Shepard ELC, Wilson RP, Quintana F, Gómez Laich A and others (2008a) Identification of animal movement patterns using tri-axial accelerometry. Endang Species Res 10:47-60

Shepard ELC, Wilson RP, Halsey LG, Quintana F and others (2008b) Derivation of body motion via appropriate smoothing of acceleration data. Aquat Biol 4:235-241

Shepard ELC, Wilson RP, Liebsch N, Quintana F, Laich AG, Lucke K (2008c) Flexible paddle sheds new light on speed: a novel method for the remote measurement of swim speed in aquatic animals. Endang Species Res 4:157-164

Simeone A, Wilson RP (2003) In-depth studies of Magellanic penguin (Spheniscus magellanicus) foraging: Can we estimate prey consumption by perturbations in the dive profile? Mar Biol 143:825-831

Stephens DW, Brown JS, Ydenberg RC (2007) Foraging: behavior and ecology. University of Chicago Press, Chicago, IL

Tremblay Y, Cherel Y (2000) Benthic and pelagic dives: a new foraging behaviour in rockhopper penguins. Mar Ecol Prog Ser 204:257-267

Walker BG, Boersma PD (2003) Diving behavior of Magellanic penguins (Spheniscus magellanicus) at Punta Tombo, Argentina. Can J Zool 81:1471-1483

Watanuki Y, Takahashi A, Daunt F, Wanless S, Harris M, Sato K, Naito Y (2005) Regulation of stroke and glide in a foot-propelled avian diver. J Exp Biol 208:2207-2216

> Watanuki Y, Wanless S, Harris M, Lovvorn JR, Miyazaki M, Tanaka H, Sato K (2006) Swim speeds and stroke patterns in wing-propelled divers: a comparison among alcids and a penguin. J Exp Biol 209:1217-1230

Williams TD (1995) The penguins. Oxford University Press, Oxford

Wilson RP (2003) Penguins predict their performance. Mar Ecol Prog Ser 249:305-310

Wilson RP, Duffy DC (1986) Prey seizing in African penguins Spheniscus demersus. Ardea 74:211-214

Wilson RP, Zimmer I (2004) Inspiration by Magellanic penguins: reduced swimming effort when under pressure. Mar Ecol Prog Ser 278:303-307

Wilson RP, Ryan PG, James A, Wilson MPT (1987) Conspicuous coloration may enhance prey capture in some piscivores. Anim Behav 35:1558-1560

Wilson RP, Hustler K, Ryan PG, Burger AE, Noldeke EC (1992) Diving birds in cold water: Do Archimedes and Boyle determine energetic costs? Am Nat 140:179-200

Wilson RP, Pütz K, Peters G, Culik B, Scolaro JA, Charrassin JB, Ropert-Coudert Y (1997) Long-term attachment of transmitting and recording devices to penguins and other seabirds. Wildl Soc Bull 25:101-106

Wilson RP, Ropert-Coudert Y, Kato A (2002a) Rush and grab strategies in foraging marine endotherms: the case for haste in penguins. Anim Behav 63:85-95

Wilson RP, Steinfurth A, Ropert-Coudert Y, Kato A, Kurita M (2002b) Lip-reading in remote subjects: an attempt to quantify and separate ingestion, breathing and vocalisation in free-living animals using penguins as a model. Mar Biol 140:17-27

Wilson RP, Kreye JA, Lucke K, Urquhart H (2004) Antennae on transmitters on penguins: balancing energy budgets on the high wire. J Exp Biol 207:2649-2662

> Wilson RP, White CR, Quintana F, Halsey LG, Liebsch N, Martin GR, Butler PJ (2006) Moving towards acceleration for estimates of activity-specific metabolic rate in free-living animals: the case of the cormorant. J Anim Ecol 75: 1081-1090

> Wilson RP, Shepard ELC, Liebsch N (2008) Prying into the intimate details of animal lives: use of a daily diary on animals. Endang Species Res 4:123-137

Ydenberg RC, Dill LM (1986) The economics of fleeing from predators. Adv Stud Behav 16:229-249 